\title{
Tombamentos, processos, disputas e tensões nas histórias do patrimônio cultural de Joinville - outras questões para o debate público
}

\author{
Tombs, processes, disputes and tensions in Joinville's cultural heritage stories - \\ other issues for public debate \\ Cristiano Viana Abrantes ${ }^{1}$ \\ Dietlinde Clara Rothert ${ }^{2}$ \\ Giane Maria de Souza ${ }^{3}$
}

\begin{abstract}
Resumo: Este artigo analisa as múltiplas variáveis dos sentidos históricos nos processos de tombamentos e inventariamentos do patrimônio cultural de Joinville, Santa Catarina, no conjunto de suas políticas públicas. O texto reflete a criação da Lei Municipal nº1773/1980 que institui a Comissão do Patrimônio Histórico Artístico, Arqueológico e Natural (COMPHAN) e a criação da Fundação Cultural de Joinville (FCJ) em 1982, atual Secretaria de Cultura e Turismo (Secult) e da Coordenação do Patrimônio Cultural (CPC) em 1997 e os processos interrompidos e inacabados de algumas políticas públicas. Analisa à luz do tempo presente, a incumbência legal da CPC e da Secult, considerando os atores, os lugares, os bens culturais e os conceitos de patrimonialização constantemente reconfigurados nestes processos históricos por técnicos, sociedade civil, políticas de gestão, historiadores e investigadores da área. Ao refletir sobre as disputas e tensões no campo patrimonial, evidencia-se distintos interesses da sociedade civil e do Estado, contrastados e mediados por técnicos, gestores $\mathrm{e}$ historiadores e deliberados pela COMPHAN.

Palavras Chave: Coordenação do Patrimônio Cultural. Inventário do Patrimônio Cultural. Políticas Públicas. Comissão do Patrimônio Histórico Artístico, Arqueológico e Natural.
\end{abstract}

\begin{abstract}
This article analyzes the multiple variables of the historical meanings of the processes of tombamentos and inventories of the cultural heritage of Joinville, Santa Catarina in the set of its public policies. The text reflects the creation of the Municipal Law $n^{\circ}$. 1773/1980, which establishes the Committee on Artistic, Archaeological and Natural Historical Heritage (COMPHAN) and the creation of the Cultural Foundation of Joinville (FCJ) in 1982, the current Secretary of Culture and Tourism (Secult) and of the Coordination of Cultural Heritage (CPC) in 1997 and the interrupted and unfinished processes of some public policies. It analyzes the light of the present time, the legal responsibility of CPC and Secult, considering the actors, places, cultural assets and concepts of patrimonialization constantly reconfigured in these historical processes by technicians, civil society, management policies, historians and researchers of the area. When reflecting on the disputes and tensions in the patrimonial field, different interests of the civil society and of the State are evidenced, contrasted and mediated by technicians, managers and historians and deliberated by COMPHAN.
\end{abstract}

Keywords: Coordination of Cultural Heritage. Inventory of Cultural Heritage. Public policy. Artistic, Archaeological and Natural Historical Heritage Committee.

\footnotetext{
1 Professor do Colégio Conexão e historiador da Secretaria de Cultura e Turismo - Coordenação de Patrimônio Cultural (CPC). E-mail: cristiano.cpcjoinville@gmail.com.

${ }^{2}$ Historiadora e especialista cultural (restauro e conservação) da Secretaria de Cultura e Turismo Coordenação de Patrimônio Cultural (CPC). E-mail: dietlinde.rothert@gmail.com.

${ }^{3}$ Doutoranda em História pela Universidade Federal de Santa Catarina (UFSC), bolsista do Programa Institucional de Doutorado Sanduíche no Exterior - PDSE/CAPES no ISCTE-IUL - Instituto Universitário de Lisboa. Especialista cultural (museus) da Secretaria de Cultura e Turismo - Coordenação de Patrimônio Cultural (CPC) - Setor de Patrimônio Imaterial. E-mail: gianehist@gmail.com.
} 


\section{Introdução}

Em maio de 2017 foi realizado o II Seminário de Políticas Culturais em Museus e Espaços de Memória “A função social dos museus e histórias controversas: dizer o indizível”, promovido pelo Sistema Municipal de Museus de Joinville (SMM/JLLE), em parceria com o Mestrado em Patrimônio Cultural e Sociedade da Universidade da Região de Joinville (Univille), enquanto Programação Nacional da 15. ' Semana Nacional de Museus do Instituto Brasileiro de Museus (Ibram). Na ocasião os técnicos Cristiano Viana Abrantes, historiador e Dietlinde Clara Rothert, especialista cultural em restauro e conservação da Coordenação de Patrimônio Cultural (CPC), unidade da Secretaria de Cultura e Turismo da Prefeitura de Joinville, apresentaram a palestra "História e atribuições da Coordenação do Patrimônio Cultural”.

Dessa atividade foi escrito um artigo por Cristiano Abrantes cujo conteúdo foi atualizado e renomeado para "Processos, disputas e tensões sobre a história do patrimônio cultural de Joinville". O texto, como resultado dessas reflexões técnicas, foi inscrito como comunicação no "Simpósio Patrimônio Cultural: Representações, Apropriações e Disputas", coordenado pelas professoras doutoras Sandra P. L. de Camargo Guedes (Univille) e Janice Gonçalves (Udesc), no XVII Encontro Estadual de História da Associação Nacional de História (ANPUH).

Na referida instância foi debatido os pontos de vistas técnico e teórico que incidem sobre as políticas de patrimônio cultural no que se refere gestão, pesquisa e profissionalização nos processos de tombamento e inventariação do patrimônio cultural na cidade de Joinville, localizada no nordeste de Santa Catarina. A partir da história de institucionalização das políticas patrimoniais na cidade, o presente artigo foi atualizado com as novas reflexões propostas pelos técnicos e as trocas de experiências ocorridas entre os colegas historiadores no Encontro Estadual de História e no simpósio temático com o intuito de ampliar as escalas de análises sobre o patrimônio cultural, memória e democracia, tendo como ponto de reflexão a construção de políticas culturais no âmbito municipal.

Nessa nova versão para Fronteira: Revista Catarinense de História, o presente texto foi metodologicamente dividido em dois momentos de análise: 1) A construção legal do patrimônio cultural; 2) Mediação Cultural e Educação Patrimonial. Essas duas seções se propõem, sobretudo, a trabalhar as construções históricas do patrimônio cultural

\footnotetext{
${ }^{4}$ Agradecemos as sugestões de revisão de Karenina Urriola Mendez e de Viviane Rodrigues em relação ao texto.
} 
em Joinville e suas múltiplas ressignificações no campo patrimonial no âmbito técnico e teórico e contribuir para o debate público.

\section{A construção legal do patrimônio cultural}

Com o estabelecimento do Estado Novo (1937-1945) muitas políticas culturais foram criadas em vários âmbitos de interesse. A instituição do Decreto-Lei n. ${ }^{\circ}$ 25, de 30 de novembro de 1937, forneceu suporte legal para a implantação e a organização das políticas de patrimônio cultural na sociedade brasileira, criando nesse aparato legal o Serviço de Patrimônio Histórico e Artístico Nacional (SPHAN) e o seu conselho consultivo. As legislações estaduais e municipais foram criadas à luz do decreto-lei federal, considerando os parâmetros legais para o reconhecimento, o tombamento e a preservação.

Para Fonseca (2005), a criação do SPHAN em 1937 reverberou uma aura preservacionista muitas vezes calcada no movimento modernista arquitetônico, que buscava contrapor o moderno com a preservação de alguns sítios históricos coloniais de imigração europeia, privilegiando em grande medida o barroco. Porém a discussão do patrimônio cultural no Brasil remete ao século XIX e à busca pela ideia de brasilidade, já com a criação do Instituto Histórico e Geográfico Brasileiro (IHGB) em 1838 (GUIMARÃES, 1988). Dessa forma, os sentidos das múltiplas brasilidades incorreram em celebrações do que seria considerada cultura nacional, conforme destaca Cury (2002). Para Fernandes (2010), a produção historiográfica do IHGB e os concursos de monografias procuravam identificar essa suposta brasilidade ou as singularidades das perspectivas nacionais. Assim, a atuação dos membros conselhistas do IHGB refletia suas posições políticas.

Do século XIX ao século XXI muitas questões foram desenvolvidas no âmbito do patrimônio cultural, as quais impulsionaram a criação de diversas instituições de patrimônio cultural pelo país, como museus, arquivos e órgãos de patrimônio, além de políticas públicas para a área. Consequentemente, os sentidos das brasilidades e regionalidades foram ressignificados no que tange aos valores patrimoniais no campo da história, arqueologia, arquitetura e artes, conforme o Decreto-Lei n. ${ }^{\circ}$ 25/1937 (BRASIL, 1937).

Esse aparato legal, ao organizar e instituir o estatuto do tombamento inseriu muitas questões na sua formatação. O desenvolvimento da política nacional de preservação do patrimônio cultural trouxe inúmeras questões sociais e econômicas à tona. 
Exclusões e escolhas tornaram-se ponto de partida para a operacionalização do decretolei. No entanto o que deve ou não ser preservado sob a chancela do Estado inseriu novos sentidos e valores patrimoniais no campo do patrimônio cultural, os quais desencadearam disputas e mobilizações sociais entre as escolhas e exclusões da atuação estatal. Diversas percepções e conflitos sociais foram oriundos da gênese e do desenvolvimento das políticas de patrimônio cultural no Brasil, em estados e em munícipios.

Tais questões em Santa Catarina se reverberaram com a criação da Lei Estadual n. ${ }^{\circ}$ 5.846, de 22 de dezembro de 1980, e em Joinville com a Lei Municipal n. ${ }^{\circ} 1.773$, de 1. de dezembro de 1980, que instituiu a Comissão do Patrimônio Histórico Artístico, Arqueológico e Natural de Joinville (COMPHAAN). Essas prerrogativas legais estruturaram os tipos e as categorias de tombamento municipal sob a supervisão e orientação do órgão federal. Sendo que:

É de competência da Secretaria de Cultura, Esporte e Turismo, por via do Serviço do Patrimônio Histórico, Artístico e Cultural, ouvida a Comissão Municipal do Patrimônio Histórico, Arqueológico, Artístico e Natural, do Município, a aplicação e o cumprimento deste diploma legal (JOINVILLE, 1980).

O trabalho da COMPHAAN, a partir do decreto municipal, seria subsidiado tecnicamente pela Secretaria de Cultura, Esporte e Turismo de Joinville. Em 1982 ocorreu mudança no quadro administrativo da Prefeitura de Joinville: a Secretaria de Cultura foi extinta, e no seu lugar foi criada a Fundação Cultural de Joinville (FCJ). Tal instituição recebeu as atribuições e responsabilidades legais da antecessora em relação à preservação do patrimônio cultural no munícipio.

Em Joinville um dos principais trabalhos realizados pelo Instituto do Patrimônio Histórico e Artístico Nacional (IPHAN) e pela Fundação Catarinense de Cultura (FCC), criada pelo Decreto Estadual n. ${ }^{\circ}$ 7.439, de 24 de abril de 1979, aconteceu nas décadas de 1980 e 1990.

Foram desenvolvidos inúmeros projetos de pesquisa para o reconhecimento das múltiplas identidades regionais, a exemplo dos "Inventários das correntes imigratórias em Santa Catarina”. Joinville, uma das cidades inclusas em tais correntes, privilegiou o estudo que iniciava em São Francisco do Sul, seguindo ao norte pela antiga estrada Dona Francisca. A pesquisa iniciou em 1984 e inventariou, aproximadamente, 80\% dos imóveis que atualmente compõem o cadastro de Unidades de Interesse de Preservação (UIPs) do munícipio de Joinville. 
Em meados da década de 1990, o estado por meio da FCC, iniciou inúmeros processos de tombamento em imóveis rurais e urbanos em Joinville. Durante o período de 1994 a 1998 a Prefeitura de Joinville, por meio da FCJ, iniciou a estruturação da Coordenação do Patrimônio Cultural (CPC), unidade responsável pela operacionalização das políticas públicas resultantes da Lei n. ${ }^{\circ} 1.773 / 1980$ e pela continuidade do levantamento histórico e arquitetônico dos imóveis integrantes das UIPs.

Em meados dos anos 2000 estruturando-se dentro das premissas da democracia participativa, a COMPHAAN foi se transformando em conselho paritário, composto por membros do poder público e da sociedade civil, com a atribuição de estudar, debater, fiscalizar e deliberar as questões relacionadas ao patrimônio cultural municipal.

No entanto, desde a criação da COMPHAAN, o patrimônio cultural imóvel municipal pode ser percebido como um caleidoscópio, impregnado de subjetividades valorativas de caráter político e econômico que resultaram em inúmeras negociações institucionais do poder público com a sociedade civil. Muitos conflitos institucionais foram gestados nos processos de patrimonialização e no gerenciamento das políticas públicas de preservação. Contudo é necessário ponderar, conforme refletem Ribas e Sousa Filho (2014): “A política pública não se confunde com o plano, o programa ou a norma, que são, normalmente, os instrumentos pelos quais elas se exteriorizam". As políticas públicas estão presentes nos processos pelos quais se escolhe a sua implantação na atuação do Estado, sociedade civil, agentes públicos e privados, no que tange os dinamismos da democracia.

Por isto, entende-se que as tensões e negociações surgem desde a elaboração do aparato legal até os trâmites dos processos patrimoniais, principalmente sobre o direito de propriedade e operacionalização das leis. Muitos processos de tombamento foram questionados por meio de argumentação jurídica, fundamentados no artigo $5 .^{\circ}$ da Constituição Federal, que aborda a questão da propriedade privada (BRASIL, 1988). O debate público realizado na COMPHAAN evidenciou uma arena política com muitas reflexões e questionamentos sobre a validade legal ou não da intervenção pública em um bem privado, assim como trouxe à tona muitos interesses de mercado imobiliário, indagações e insatisfações da sociedade civil quanto às políticas da administração municipal.

Diante desse quadro, muitos setores da sociedade civil foram mobilizados em disputas de interesses privados e públicos. As histórias do patrimônio cultural da cidade 
tornaram-se fruto de negociações, barganhas, reivindicações e negações, como demonstram os trabalhos de Radun (2016), Machado (2009; 2016) e Silva (2016).

Gonçalves (2016, p. 185), por sua vez, ao analisar as atuações do órgão do patrimônio federal em Santa Catarina, manifestou a existência de "curto-circuitos comunicativos" entre o poder público federal, estadual, municipal, a sociedade civil, os profissionais de patrimônio e os proprietários de imóveis. Segundo a autora, mesmo considerando as trajetórias legais e institucionais, o patrimônio não pode ser considerado sob o aspecto linear, tampouco contínuo. Apoiada em Bourdieu, a autora desenvolveu análises sobre as crenças ressoadas no campo do patrimônio no âmbito das trocas simbólicas, sociais, culturais e econômicas. Tais crenças nos sentidos de preservação transformam o patrimônio cultural em figuras de valor, conforme os critérios estabelecidos, a exemplo de excepcionalidade designada pelo Decreto-Lei n. ${ }^{\text {o }}$ 25/1937. Por isso, destaca:

Esquadrinhar esse cenário com frequência conturbado, particularmente aberto a contestações, disputas, confrontos e litígios, pode contribuir, entre outros aspectos, para compreender o papel desempenhado pelas instâncias governamentais incumbidas da proteção de bens culturais, para detectar os problemas gerados em suas ações e, enfim, permitir repensar, reformular e reconfigurar concepções e práticas.

Para Bourdieu (1996; 2015), a produção e a circulação dos bens culturais estruturam o campo e o capital simbólico da cultura como campo de legitimação e consagração de intelectuais, artistas, bens culturais e mercado. Refletindo sobre a esfera das artes, o sociólogo analisa quem determina o valor da obra de arte, quem cria ou quem consagra. Tal reflexão auxilia a pensar o âmbito do patrimônio cultural e seus valores de criação e chancela estatal como instâncias de consagração, juízo de mercado e produção de fetiche.

Gonçalves (2016) e Meneses (2009) trabalham sob a perspectiva do valor, entre o que deve ou não ser patrimonializado. As reflexões de ambos os autores consideram as múltiplas tensões entre os equipamentos culturais e o turismo, entre quem trabalha e usufrui e entre o Estado e a sociedade civil. Os desafios teóricos e políticos confrontam as crenças de pertencimento, de usufruto, do proprietário e do gestor público. Processos de inventariação e tombamento trazem o protagonismo do poder público, por conta do Decreto n. ${ }^{\circ}$ 25/1937, mas trazem também a agência da sociedade civil na coparticipação do processo - tendo em vista que nem tudo que o poder público elabora como memória 
coletiva é de fato memória pública de reconhecimento coletivo, mas uma memória individual, baseada em crenças de valores privados.

Meneses (2009, p. 32) reitera a ideia de que o patrimônio deve ser tratado como um fato social. E, como tal, a questão do valor será sempre "espinhosa” para quem lhe dá valor e para quem lhe atribui sentidos, já que quando um bem cultural é tombado a escala de valor aumenta sob o ponto de vista de uns e diminui pela perspectiva de outros. Inúmeros questionamentos de valor são gerados sobre a interferência no direito de propriedade, principalmente a forma compulsória do Estado na chancela do bem cultural.

Estaríamos diante de uma nova polaridade: valor técnico versus valor social? Não ainda, mas o risco está presente. Por isso julgo premente começarmos a rever nossa postura a respeito do valor e da avaliação (reconhecimento do valor), sem excluir a perspectiva do especialista, obviamente, mas sempre privilegiando aquela do usuário, do fruidor [...] (MENESES, 2009, p. 34)

Por isso, pesquisar e trabalhar com patrimônio cultural requer uma compreensão alargada da percepção de coletivo e individual, de público e privado, crenças e idiossincrasias, interesses e demandas, memória e memórias, identidade e identidades, considerando a questão de que o patrimônio se forma sob a base da desigualdade da inclusão e exclusão.

Desta forma, torna-se salutar rediscutir a questão da transmissão e da fruição cultural, dos papéis dos intelectuais, dos profissionais, dos gestores, dos lugares de memória onde circulam saberes e fazeres, ideias para estabelecer o conceito de mediador cultural e abrir novas perspectivas de refletir sobre os papéis desempenhados pelos técnicos e historiadores no âmbito do patrimônio cultural e da história do tempo presente. Para Padrós (2009, p. 35): “A função primordial do historiador (e é claro, também do historiador do presente) não é julgar o passado e sim decodificá-lo, interpretá-lo e explicálo.”

Nesse sentido Delgado e Moraes Ferreira (2014, p. 9), apresentam historiadores e intelectuais em múltiplos temas que abordam história e tempo presente como uma versatilidade de se trabalhar fenômenos contemporâneos, como por exemplo, patrimônio cultural, cultura política e políticas públicas.

Isso porque o tempo presente constitui-se como realidade temporal propícia à construção de relatos e registros de lembranças. São vozes múltiplas, que muitas vezes registram formas diferentes e até conflitantes de rememoração de acontecimentos e processos. Portanto, podem ser identificados como documentos que, por trazerem em si diversidade de visões do mundo e de registros das experiências vividas, valorizam a heterogeneidade em detrimento de uma 
homogeneidade que usualmente simplifica e distorce o mundo real.

Com este pressuposto teórico, apresentam-se questões que podem ser problematizadas dentro do âmbito da história pública e do tempo presente como processos de gestão, de elaboração de políticas de memória, de patrimonialização e de participação social. No entanto, estas reflexões teóricas, colocam outra de ordem prática: como avaliar os papéis sociais que os pesquisadores, os trabalhadores, os gestores e a sociedade civil desempenham em mecanismos como os conselhos de políticas públicas?

Em Joinville, a Coordenação de Patrimônio Cultural atualmente contabiliza cerca de cinco processos de imóveis judicializados - um número razoavelmente pequeno para a quantidade de conflitos noticiados pelos meios de comunicação em relação às disputas pelas múltiplas memórias da cidade sejam elas, coletivas ou individuais, públicas ou privadas. Muitos destes embates são protagonizados no âmbito do debate público, nas reuniões da COMPHAAN, nos fóruns e nas conferências de cultura.

Contudo ao avaliar as análises históricas realizadas sobre os mecanismos de preservação municipal, observa-se que o trabalho técnico desenvolvido desde a década de 1980 foi continuadamente utilizado como fonte de pesquisa. Muitas pesquisas historiográficas, sociológicas, arquitetônicas e antropológicas foram realizadas a partir da interpretação das fontes documentais produzidas pelo trabalho técnico, assim como alguns pesquisadores de Joinville já foram gestores culturais de forma sincrônica ou diacrônica às suas carreiras acadêmicas, facilitando o acesso às fontes e ao percurso realizado pelo trabalho técnico. Já a sociedade civil, foi copartícipe da elaboração do aparato legal municipal de políticas públicas, assim como da implantação de equipamentos culturais, desde a fundação da cidade em 1851. Essas questões evidenciam que as histórias e as memórias acerca do patrimônio cultural são constantemente apropriadas, seja por técnicos, pesquisadores ou pela sociedade civil em seus processos de construções identitárias.

Dessa forma, se houve participação, representação social e cogestão na implantação e deliberação sobre as políticas culturais, conclui-se que os inventários e tombamentos realizados pela COMPHAAN fazem parte desse processo de constituição de políticas públicas. Num panorama amplo, muitos bens patrimoniais foram preservados por conta da atuação de gestores, técnicos, pesquisadores e agência da sociedade civil. Já a COMPHAAN, enquanto uma instância participativa de poder, ampara-se no estabelecimento, na mediação e no equilíbrio das forças sociais em disputa, sejam elas 
reivindicações dos gestores, pesquisadores, técnicos e sociedade civil. Contudo a participação e representação da sociedade civil dentro da COMPHAAN são sempre delegadas por instituições afins, como prevê seu regimento, neste caso, são múltiplos horizontes de expectativas e espaços de experiências que emergem destas instituições para esse espaço político, conforme reflexão a partir das categorias de Koselleck (2006).

Por isso é necessário estabelecer um cruzamento histórico dos papéis sociais desempenhados pelos agentes públicos e privados para demonstrar que existem pontos de partida, espaços de experiências e múltiplos horizontes de expectativas em disputa. $\mathrm{O}$ processo democrático que se estabeleceu após a Constituição de 1988 (CF-1988) propicia e impulsiona o debate político em mecanismos de participação social.

Destarte, com a inclusão constitucional dos artigos 215 e 216 na CF-1988 sobre patrimônio material e imaterial, algumas palavras tornaram-se evocadas no plural no âmbito da democracia representativa e participativa. Nacionalidades, identidades, memórias, histórias, brasilidades, imigrações, comunidades, entre outras, demarcam que a pluralidade cultural redimensionou as políticas de patrimônio cultural. E com o Decreto n. ${ }^{\circ}$ 3.551, de 4 de agosto de 2000, foi instituído o Programa Nacional de Patrimônio Imaterial para o reconhecimento de fazeres, saberes, ofícios, lugares, manifestações e expressões culturais, reorientando as políticas estaduais e municipais no campo do patrimônio.

Com base nessa abrangência legal, Chuva (2011, p. 152) reflete:

$\mathrm{Na}$ atualidade, a área do patrimônio engloba um conjunto significativo de questões de ordem política, de relações de poder, de campos de força e âmbitos do social. Anteriormente alheio a essa prática, hoje o patrimônio toma em consideração questões relativas à propriedade intelectual, ao meio ambiente, aos direitos culturais, aos direitos difusos, ao direito autoral, ao impacto cultural causado por grandes empreendimentos, além dos temas já tradicionais, como aqueles que envolvem questões de urbanismo e uso do solo, expansões urbanas sobre áreas históricas decadentes, questão histórica em áreas históricas urbanas e, principalmente, os limites que o tombamento impõe à propriedade privada.

Joinville, seguindo o que determina o Sistema Nacional de Cultura (SNC) e o Plano Nacional de Cultura (PNC) com o intuito de implantar uma política de patrimônio cultural material e imaterial, instituiu a Lei Municipal Complementar n. ${ }^{\circ}$ 363, de 11 de dezembro de 2011, para organizar o Inventário do Patrimônio Cultural de Joinville (IPCJ), e a Lei Complementar n. ${ }^{\circ} 366$, para estabelecer benefícios fiscais aos proprietários 
de imóveis, mediante a conservação do bem protegido ${ }^{5}$. A Lei do IPCJ, além de organizar juridicamente os processos de inventários, também determinou prazos para o cumprimento dos processos administrativos sob a responsabilidade do munícipio ${ }^{6}$.

As Leis do IPCJ constituíram um mecanismo amplamente debatido e apurado em reuniões da COMPHAAN, do Conselho Municipal de Política Cultural (CMPC), dos Fóruns Públicos de Patrimônio Cultural, Museus e Espaços de Memória e nas Conferências Municipais de Cultura, a exemplo da esfera federal. Dessa forma, houve uma participação social e democrática relevante no debate político sobre esse conjunto legal. As leis foram ratificadas no Plano Municipal de Cultura, instituído por Lei Ordinária n. ${ }^{\circ} 7.258$, de 6 de julho de 2012, cuja meta de número 2 determina:

Inventário do Patrimônio Cultural de Joinville (IPCJ) 100\% implementado como mecanismo de conhecimento e proteção, com registro de bens culturais materiais móveis e imóveis e registro de saberes, celebrações, formas de expressão e lugares reconhecidos como patrimônio imaterial do município (JOINVILLE, 2012).

No entanto as metas do PNC e as leis vinculadas ainda não foram alcançadas em sua plenitude, mesmo sendo reivindicadas em fóruns e conferências públicas de cultura, por meio de moções e proposições aprovadas nas suas respectivas plenárias finais. Não obstante, a Lei Complementar n. ${ }^{\circ}$ 495, de 16 de janeiro de 2018, extinguiu a Fundação Cultural de Joinville e em seu lugar recriou a antiga Secretaria de Cultura e Turismo, dessa vez sem a pasta do Esporte, mas demarcando novas configurações administrativas no desenho institucional da gestão em cultura do munícipio. Essas mudanças conjunturais e de reformas administrativas demarcaram novos interesses e disputas políticas em relação aos sentidos da patrimonialização em sua organização e interpretação do aparato legal.

Contudo as interferências políticas e de mercado historicamente tornam o patrimônio cultural um campo de litígio judicializado e contestado, além das crenças e das disputas pelas memórias coletivas e individuais advindas desse processo. Para ilustrar essa questão, o caso da "Casa Amarela" e do "Bar Tigre” é emblemático. Esses imóveis tornaram-se objetos de litígio entre 2007 e 2008 por conta da construção do Angeloni Supermercados. O imóvel popularmente conhecido como "Casa Amarela” construído em

\footnotetext{
${ }^{5}$ Essa lei até o presente momento não foi regulamentada em parte.

6 Tal processo está em andamento, e os prazos não foram cumpridos, por problemas relacionados às sucessivas trocas de gestão na gerência de Patrimônio Cultural e Museus e na coordenação da CPC.
} 
1908 e inserido no Cadastro das Correntes imigratórias de 1983 estava em processo de tombamento pela FCJ. Já o "Bar Tigre", tornou-se questionado pela função social que o imóvel possuía, não por suas características arquitetônicas e de referência cultural histórica. Nesse processo, especificamente, observou-se a difusão de diferentes opiniões públicas por meio da imprensa (A NOTÍCIA, 2008a; 2008b) sobre a demolição do bem cultural, inclusive noticiando divergências de encaminhamentos e posições entre os técnicos e gestores da Fundação Cultural de Joinville e do Instituto de Planejamento e Pesquisa para o Desenvolvimento Sustentável (IPPUJ), a FCJ defendia a preservação, já o IPPUJ a demolição. A imprensa local, durante 18 meses trabalhou as disputas em torno desses imóveis como se o patrimônio cultural provocasse um empasse para o desenvolvimento econômico ${ }^{7}$.

Além de todas essas questões, observa-se no trabalho cotidiano, que a desinformação jurídica em relação às leis e dos procedimentos técnicos muitas vezes cruza as esferas de mediação política entre o poder público e a sociedade civil, como "curto-circuito comunicativos" pontuados por Gonçalves (2016). Constantes trocas de gestores e conselheiros no setor de patrimônio cultural, igualmente, atravancam os processos de inventariamentos e tombamentos, pois há uma necessidade em cada mudança de gestores ou de conselheiros, de iniciar o processo pedagógico patrimonial desde o início. Algumas vezes, o gestor e o conselheiro não possuem domínio técnico, tampouco, a sociedade civil, por isso a mediação cultural e educação patrimonial tornamse fundamentais para a salvaguarda do trabalho em andamento. No caso de Joinville, a demanda de trabalho do setor de patrimônio material da CPC, por conta do IPCJ, aumentou gradativamente e os processos de inventariação são encaminhados quinzenalmente para análise e apreciação dos conselheiros na COMPHAAN.

No tempo presente, essa demanda de trabalho técnico pode ser vislumbrada pela quantidade de processos de patrimonialização. São aproximadamente cem imóveis tombados ou inventariados, mais uma lista com mil UIPs aguardando estudos e análises técnicas para adequação na nova Lei de Ordenamento Urbano (LOT). Isso faz com que a administração do patrimônio municipal seja ainda mais "espinhosa", como refletiu Meneses (2009).

\footnotetext{
7 Dias (2016), realizou outras abordagens e análises em torno das "representações sociais" veiculadas pelos jornais locais em torno dessas disputas.
} 


\section{Mediação cultural e educação patrimonial}

Para a atuação com patrimônio cultural é necessário estabelecer no cotidiano da prática institucional um jogo de mediação cultural, para que o trabalho de pesquisa, fiscalização e salvaguarda não seja comprometido com as inconstâncias políticas, crenças, preconceitos e disputas sociais inseridas no desenvolvimento das políticas públicas. Muitas revisões de premissas e metodologias refazem caminhos já traçados pelos agentes públicos nas histórias do patrimônio cultural de Joinville. Tanto na perspectiva acadêmica quanto técnica, os caminhos cruzam-se e são reinventados. Nesse percurso a implantação da Lei do IPCJ foi reivindicada e contestada por múltiplos setores da sociedade.

O trabalho técnico é fundamental para a produção de fontes historiográficas, para futuras análises e contrapontos de investigadores da área. Assim como, é realizada uma curadoria de fontes pelos técnicos quando se inicia um processo de inventariação, para o levantamento de pesquisas histórico-culturais e arquitetônico-urbanísticas. Os trabalhos são complementares e problematizadores do campo do patrimônio. Os trabalhos historiográficos, como teses e dissertações, tornam-se importantes para refletir sobre as múltiplas histórias institucionais pelas quais o patrimônio cultural de Joinville desde o século passado foi forjado. Mas, o trabalhador técnico, diante de tais questões, torna-se um guardião do patrimônio cultural da cidade e da memória institucional das políticas culturais que são geridas ao longo do tempo.

Neste sentido, a categoria de mediador cultural constituída na obra de Gomes e Hansen (2016, p. 9), com base em Jean-Françoise Sirinelli, pelas práticas culturais desenvolvidas podem ser uma chave de compreensão dos profissionais que atuam com patrimônio cultural. As autoras realizam dois esclarecimentos em relação a essa categoria:

O primeiro deles é o de que reconhecemos que as práticas de mediação cultural podem ser exercidas por um conjunto diversificado de atores, cuja presença e importância nas várias sociedades e culturas tem grande relevância, porém, nem sempre reconhecimento. No que diz respeito às relações com o passado, esse é o caso, por exemplo, do chamado "guardiões da memória" familiar, encarnados em pessoas idosas ou em um membro da família que estabelece como seu objetivo "produzir", de maneira mais ou menos informal, um arquivo de documentos ou de relatos sobre a história dessa família. Isso pode ocorrer igualmente em grupos sociais de várias naturezas, nos quais indivíduos se dedicam a "colecionar" objetos e a produzir relatos memoriais, escritos ou registrados em outro suporte, com alguma circulação entre o grupo, além de certa permanência no tempo. Outros mediadores culturais podem ser identificados nos leitores, contadores de 
histórias, guias de instituições, pais e outros agentes educadores encarregados da socialização de crianças e jovens em diversas situações. Tais mediadores, de enorme relevância na construção de identidades culturais de indivíduos e comunidades, geralmente não são identificados e não se identificam pela categoria de intelectual.

Destarte, pode-se considerar que os técnicos que atuam profissionalmente no patrimônio cultural podem ser considerados dentro desta clave argumentativa da categoria de mediadores culturais, na perspectiva daquilo que as autoras classificam como técnicos, uma espécie de guias institucionais e colecionadores. Como colecionadores, os técnicos atuam como guardiães na salvaguarda dos processos inventariados, desde a abertura dos processos até o arquivamento e a disponibilização pública para pesquisa historiográfica e para a consulta pública, na produção técnica de pesquisa arquitetônica, histórica, no arrolamento e classificação de bens culturais, nos processos de inventários, nas fiscalizações, sistematizações de orientações técnicas aos bens tombados, no atendimento aos munícipes, na produção de história oral, na educação patrimonial, realizações de vistorias e na elaboração de laudos e processos para serem enviados para análise da COMPHAAN. Assim, muita produção técnica foi elaborada e disponibilizada para a sociedade civil, para os gestores e pesquisadores por meio do trabalho técnico enquanto mediação cultural.

Já na condição de guias, os técnicos, muitas vezes qualificam a relação do poder público com a sociedade civil. Sendo que todos os processos, primeiramente, são analisados e organizados, pelos técnicos. Existe uma travessia necessária nas relações e nas conduções das políticas públicas: o olhar técnico, o olhar cidadão e o olhar do gestor. Esses três olhares quando considerados de forma democrática na condução das políticas públicas, auxiliam a sua implementação. Por isso, os técnicos são efetivamente os operacionalizadores das políticas públicas de patrimônio cultural. As oscilações políticas nas trocas de comando das gestões públicas são muitas. A memória institucional deve ser salvaguardada. Seja como guia, colecionador, os técnicos são os profissionais que de fato tiram as letras dos decretos institucionais e as colocam na prática administrativa das políticas públicas de preservação ${ }^{8}$. O técnico, como mediador, nem sempre age na sociedade como intelectual, contudo ele atua na produção e organização das fontes que serão utilizadas pelos intelectuais e pesquisadores do campo do patrimônio cultural.

\footnotetext{
${ }^{8}$ Salvo, obviamente, as ingerências que ocorrem sobre o campo de patrimônio cultural na deliberação de algumas políticas de gestão.
} 
Há outra questão que pode emergir nesse debate de técnicos como mediadores culturais. Essa discussão pode estar inserida na produção de fontes historiográficas pelos técnicos, como por exemplo, os laudos técnicos do setor de patrimônio cultural, produzidos no inventariamento e tombamento de bens imóveis. Os resultados dos trabalhos técnicos possuem caráter científico? Gomes e Hansen (idem) contribuem para essa reflexão, principalmente quando destrincham a relação do intelectual e do mediador criada por Sirinelli. Nesse sentido, esse artigo, ao classificar o trabalho do técnico em patrimônio cultural como mediador cultural indaga e reflete sobre o processo de valoração técnica e científica conferida nos resultados dos trabalhos técnicos. Os trabalhadores e trabalhadoras podem ser compreendidos como mediadores culturais, porque o trabalho cotidiano não requer a envergadura intelectual acadêmica pleiteada em uma dissertação de mestrado ou tese de doutorado. Contudo, mesmo que os trabalhos técnicos tenham recortes temáticos e temporais reduzidos e pesquisas teóricas mais sucintas, isso não exime o trabalho técnico de ser realizado com o rigor científico, exigido na produção e difusão do conhecimento. No desenvolvimento das tarefas diárias os profissionais instrumentalizam a prática científica a partir de metodologias interdisciplinares de pesquisas, análise de fontes e pesquisas bibliográficas, realização de história oral, fundamentações teóricas, elaboração de partidos arquitetônicos, de laudos, relatórios técnicos, normatizações padronizadas e procedimentos éticos de pesquisa exigidos dentro e fora da academia. Nos processos de trabalhos e entre os saberes e fazeres dos técnicos enquanto mediação cultural pode ser evidenciada no estudo dos trabalhos de inventariamento de patrimônio cultural, seja ele, no âmbito tangível ou intangível, periodicamente apresentado às reuniões da COMPHAAN. A categorização de mediador cultural é pertinente também, quando reflete que nem sempre esse trabalho é reconhecido pela sociedade (universidades, sociedade civil organizada, gestores, instituições), como um trabalho científico, tampouco de mediação cultural.

Nesse sentido, onde se encontra a relação dos técnicos, dos historiadores, da sociedade civil e dos gestores? Evidentemente no campo da mediação cultural estabelecida pelos técnicos. Por isso, a educação patrimonial é importante para desenvolver, instigar e vislumbrar múltiplos sensos de pertencimento às políticas públicas e a corresponsabilidade coletiva pelos bens públicos, pelo diálogo e pela difusão do conhecimento. Nesse sentido, o IPHAN reflete sobre as diretrizes da educação patrimonial: 
Para tanto, as políticas de preservação devem priorizar a construção coletiva e democrática do conhecimento, por meio do diálogo permanente entre os agentes institucionais e sociais e pela participação das comunidades detentoras e produtoras das referências culturais. Nesse processo, as iniciativas educativas devem ser encaradas como um recurso fundamental para a valorização da diversidade cultural e para o fortalecimento da identidade local, fazendo uso de múltiplas estratégias e situações de aprendizagem construídas coletivamente (IPHAN, 2014, p. 22).

Assim como o trabalho dos técnicos estabelece uma prática de mediação cultural para a preservação do patrimônio, os estudos e as pesquisas desenvolvidas por instituições de ensino superior são fundamentais para ampliar a escala de análise sobre as histórias dos múltiplos patrimônios que compõem a paisagem da cidade. Além dos processos de tombamento e inventariação, os saberes e fazeres e as referências culturais e identitárias devem ser considerados na formação da diversidade cultural. Assim sendo, o cruzamento teórico com o técnico qualifica a construção das múltiplas compreensões, apreensões e usos do patrimônio cultural para a sociedade numa perspectiva educativa de elaboração do conhecimento.

Quando se estabelece o processo de educação patrimonial como mediação cultural, percebem-se mudanças de olhar e dos sentidos que o patrimônio evoca, tanto nos gestores quanto na sociedade civil. Por isso o poder público não pode se furtar ao diálogo social e à sua missão de elaborar, gerenciar e implantar as políticas públicas de forma horizontal e participativa. A educação patrimonial entende que o processo democrático auxilia na resiliência de problemas e na construção de objetivos comuns para a qualidade e a transparência da administração pública a partir da ampliação da dimensão simbólica, cidadã e econômica da cultura.

Para o trabalho técnico existem muitas dificuldades no processo de mediação entre o governo e a sociedade civil, todavia é possível pontuar escolhas e negociações para a preservação das memórias e das construções históricas legais. A memória coletiva e pública, inerentemente, passa por uma memória individual e senso de pertencimento. Assegurar as múltiplas memórias e mediar os diversos interesses torna-se prática recorrente nas administrações públicas. Entre aquilo que se quer preservar existem muitas outras histórias e trajetórias a considerar. Tal problemática está correlacionada com a construção de múltiplas brasilidades e, consequentemente, com a cisão e as disputas dos movimentos de criação das memórias nacionais desde o século XIX; portanto não é, efetivamente, uma problemática nova. 
Nessa direção, conselhos públicos na área de patrimônio cultural, como o Conselho Consultivo do IPHAN e a COMPHAAN, possuem papéis estratégicos para estimular o protagonismo social e a atuação pública democrática para a preservação dos bens culturais no âmbito da diversidade, assim como a fiscalização e o controle social na operacionalização das políticas públicas. O patrimônio cultural, como espaço de consagração e de legitimação, é eminentemente campo de exclusão e de afirmação identitária. Os conselhos auxiliam a mediação dos jogos de interesses e poderes envolvidos nos múltiplos setores das representações conselhistas.

Além dos conselhos públicos, existe uma sociedade que é múltipla e diversa, que necessita ser auscultada pelos representantes eleitos nesses espaços e nas câmaras legislativas e na gestão pública. Grupos empresariais, ramos imobiliários, setores turísticos, movimentos sociais, sindicatos, instituições de pesquisa e de ensino superior, de direitos humanos, todos possuem organizadamente seus direitos pautados conforme seus interesses. O direito à memória, à história e ao bem cultural torna-se amplo e "espinhoso", como afirmou Meneses (2009), mas constitui infinitamente os valores que o patrimônio ressoa em todos os cantos da sociedade.

Há de se refletir ainda, sobre a participação da comunidade em tais processos por meio das associações ou instituições. Como adverte Anderson (2005), não necessariamente há uma comunidade homogênea, tampouco uma comunidade fechada em si mesma. Todas as comunidades são imaginadas, transpostas, fluidas, construídas e reconstruídas das correlações de forças em disputas.

Essas questões podem ser observadas em análises e pesquisas realizadas para laudos técnicos, como nas pesquisas e publicações historiográficas, antropológicas, de direito e sociológicas, quando se debate a patrimonialização de bens e suas possíveis justificativas.

Para Canclini (2015, p. 350), é preciso perceber as práticas sociais além das atuações, como representações organizadas ou não: "Isso acontece não apenas nas atividades culturais expressamente organizadas e reconhecidas como tais; também os comportamentos ordinários, agrupados ou não em instituições, empregam a ação simulada, a atuação simbólica".

\section{Considerações finais}


O histórico legal arrolado sobre o patrimônio cultural neste artigo evidencia que o caminho legal foi construído em múltiplas tensões e disputas, desde critérios de valor atribuídos aos tombamentos, assim como a implantação e operacionalização das leis e das políticas públicas. Em uma sociedade democrática, a sociedade civil e o Estado muitas vezes se deparam com interesses divergentes, por isso, o papel da mediação cultural e da educação patrimonial desenvolvido pelos técnicos como guardiães da memória institucional é crucial para zelar pelo aparato legal constituído. Mudanças políticas frequentemente fragilizam o patrimônio cultural e suas prerrogativas legais e históricas. Alguns gestores políticos, por usa vez, entendem o patrimônio cultural sob a esfera da propriedade privada e não do sentido público da memória coletiva a ser protegida.

Nesses processos de questionamentos, de tensões e disputas pelas quais a gestão do patrimônio cultural historicamente é constituída, podem-se vislumbrar novos usos e ressignificações para a preservação dos bens culturais. O patrimônio protegido auxilia na sustentabilidade e qualidade de vida de uma sociedade diversa. Esse escopo pode ser alcançado sob a perspectiva da economia criativa e solidária, dos usos e ocupações sociais, para usufruto da comunidade, do turismo, do lazer e da difusão do conhecimento. O patrimônio preservado gera uma infinidade de recursos e relações de pertencimentos para a cidade, entretanto as relações patrimoniais devem ser geridas para a diversidade cultural e a democratização do bem público.

A dinâmica do patrimônio cultural ultrapassa detalhes e processos técnicos, análises, pesquisas historiográficas e produções científicas. Sem ressonância social não existe patrimônio cultural. Há, portanto um mundo complexo a ser desbravado e ocupado no campo patrimonial. Existem muitos editais públicos e privados que estimulam novas apropriações e usos patrimoniais, a exemplo do Sistema Municipal de Desenvolvimento para a Cultura (Simdec), que incentiva e fomenta projetos de pesquisa, de restauro em bens tombados e inventariados e de projetos educativos para o empoderamento social na preservação material e imaterial do patrimônio.

Exemplos mundiais demonstram possibilidades de conciliação da prática da preservação do bem cultural com o desenvolvimento econômico sustentável. Conjuntos arquitetônicos e históricos, a exemplo do centro de Joinville, poderiam ser repensados urbanisticamente, além das casas comerciais e residenciais, como roteiros culturais integrados aos museus, edifícios e casarões históricos tombados e inventariados experiência que já acontece em outros municípios do mesmo porte que Joinville em nível nacional e mundial. 
O patrimônio cultural pode ser reestruturado de forma coletiva, democrática e horizontal para possibilitar novas incursões culturais e sociais. Os caminhos para conciliar a preservação, o desenvolvimento e a educação patrimonial inserem-se em um processo de produção e difusão do conhecimento. Braudel (1990) nos lembra de que a cultura é a mais abrangente área da manifestação humana, por isso memórias e histórias rompem os séculos e milênios.

\section{Referências bibliográficas}

ANDERSON, Benedict. Comunidades imaginadas: reflexões sobre a origem e a expansão do nacionalismo. Lisboa: Edições 70, 2005.

BOURDIEU, Pierre. A produção da crença: contribuição para uma economia dos bens simbólicos. 3. ed. Porto Alegre: Zouk, 2015.

As regras da arte: gênese e estrutura do campo literário. São Paulo: Companhia das Letras, 1996.

BRASIL. Constituição da República Federativa do Brasil. Brasília, DF: Senado, 1988.

Decreto $n .^{\circ} 3.551$, de 4 de agosto de 2000. Institui o registro de bens culturais de natureza imaterial que constituem patrimônio cultural brasileiro, cria o Programa Nacional de Patrimônio Cultural e dá outras providências. Brasília, 2000. Disponível em: http://portal.iphan.gov.br/uploads/legislacao/Decreto_n_3.551_de_04_de_agosto_de_20 00.pdf>. Acesso em: 17 ago. 2018.

Decreto-Lei $n .^{\circ}$ 25, de 30 de novembro de 1937. Organiza a proteção do patrimônio histórico e artístico nacional. Rio de Janeiro. Capital Federal, 1937. Disponível em: <http://portal.iphan.gov.br/uploads/legislacao/Decreto_no_25_de_30_de_novembro_de _1937.pdf>. Acesso em: 15 jan. 2018.

BRAUDEL, Fernand. História e ciências sociais. Tradução portuguesa de Rui Nazaré. 6. ed. Lisboa: Presença, 1990.

BRIGAS judiciais marcaram a construção do novo Angeloni. Jornal A Notícia Online. 03 dez. 2008. Disponível em: http://anoticia.clicrbs.com.br/sc/noticia/2008/12/brigasjudiciais-marcaram-construcao-do-novo-angeloni-2317839.html Acesso em: $17 \mathrm{dez}$. 2018. a

CASA Amarela em terreno do Angeloni vai ao chão. Jornal A Notícia Online. 02 jul. 2008. Disponível em: http://anoticia.clicrbs.com.br/sc/noticia/2008/07/casa-amarela-emterreno-do-angeloni-vai-ao-chao-2018799.html Acesso em: 17 dez. 2018.b

CANCLINI, Néstor Garcia. Culturas híbridas: estratégias para entrar e sair da modernidade. São Paulo: Editora da Universidade de São Paulo, 2015. 
CHUVA, Marcia. Por uma história da noção de patrimônio cultural no Brasil. Revista do Patrimônio Histórico e Artístico Nacional, Brasília, v. 1, n. 34, p. 147-165, 2011.

CURY, Claudia Engler. Políticas culturais no Brasil: subsídios para construção da brasilidade. 175 f. Tese (Doutorado) - Universidade Estadual de Campinas, Campinas, 2002.

DELGADO, Lucilia de Almeira Neves \& FERREIRA, Marieta de Moraes. História do Tempo Presente. Rio de Janeiro: FGV, 2014.

DIAS, Maria Cristina. O patrimônio na pauta do dia: a construção de representações sobre o caso do "Bar Tigre" e da "Casa Amarela" na imprensa escrita de Joinville. 151f. Dissertação (Mestrado)-Universidade da Região de Joinville, Joinville, 2016.

FERNANDES, José Ricardo Oriá. Muito antes do SPHAN: a política de patrimônio histórico no Brasil (1838-1937). In: SEMINÁRIO INTERNACIONAL: TEORIA E PRÁXIS. Anais... Rio de Janeiro: FCRB, 2010. p. 1-14.

FONSECA, Maria Cecília Londres. A fase heroica. In: O patrimônio em processo: trajetória da política federal de preservação no Brasil. 2. ed. Rio de Janeiro: MinC - Iphan, 2005.

GOMES, Angela de Castro Gomes; HANSEN, Patrícia Santos (Orgs.). Intelectuais mediadores: práticas culturais e ação política. Rio de Janeiro: Civilização Brasileira, 2016.

GONÇALVES, Janice. Figuras de valor: patrimônio cultural em Santa Catarina. Itajaí: Casa Aberta, 2016.

GUIMARÃES, Manoel Luiz Salgado. Nação e civilização nos trópicos: o Instituto Histórico Geográfico Brasileiro e o Projeto de uma História Nacional. Rio de Janeiro, 1988. Disponível em: <http://ftp.editora.ufrn.br/bitstream/handle/>. Acesso em: 10 out. 2017.

INSTITUTO DO PATRIMÔNIO HISTÓRICO E ARTÍSTICO NACIONAL - IPHAN. Educação patrimonial: histórico, conceitos e processos. Brasília, 2014.

JOINVILLE. Lei Municipal $n .^{o} 1.773$, de $1 .^{\circ}$ de dezembro de 1980. Dispõe sobre a proteção do patrimônio histórico, arqueológico, artístico e natural do munícipio de Joinville. Joinville, $1980 . \quad$ Disponível em: $<$ https://leismunicipais.com.br/a/sc/j/joinville/lei-ordinaria/1980/177/1773/lei-ordinarian-1773-1980-dispoe-sobre-a-protecao-do-patrimonio-historico-arqueologico-artistico-enatural-do-municipio-de-joinville>. Acesso em: 25 ago. 2018.

Lei Municipal Complementar $n^{\circ} 363$, de 19 de dezembro de 2011. Institui, no âmbito do munícipio de Joinville, o Inventário do Patrimônio Cultural de Joinville (IPCJ) e dá outras providências. Joinville, 2011. Disponível em: <https://leismunicipais.com.br/a/sc/j/joinville/lei-complementar/2011/36/363/leicomplementar-n-363-2011-institui-no-ambito-do-municipio-de-joinville-o-inventario- 
do-patrimonio-cultural-de-joinville-ipcj-e-da-outras-providencias>. Acesso em: 25 ago. 2018.

Lei Municipal Complementar n. ${ }^{\circ}$ 366, de 19 de dezembro de 2011. Dispõe sobre deduções e isenções tributárias para imóveis cadastrados no Inventário do Patrimônio Cultural de Joinville (IPCJ) e dá outras providências. Disponível em: $<$ https://leismunicipais.com.br/a/sc/j/joinville/lei-complementar/2011/36/366/leicomplementar-n-366-2011-dispoe-sobre-deducoes-e-isencoes-tributarias-para-imoveiscadastrados-no-inventario-do-patrimonio-cultural-de-joinville-ipcj>. Acesso em: 25 ago. 2018.

Lei Municipal Complementar n. ${ }^{\circ} 495$, de 16 de janeiro de 2018. Modifica as estruturas administrativas e competências dos órgãos da Administração Direta e Indireta do Munícipio de Joinville e dá outras providências. Disponível em: $<$ https://leismunicipais.com.br/a/sc/j/joinville/lei-complementar/2018/49/495/leicomplementar-n-495-2018-modifica-as-estruturas-administrativas-e-competencias-dosorgaos-da-administracao-direta-e-indireta-do-municipio-de-joinville-e-da-outrasprovidencias>. Acesso em: 25 ago. 2018.

Lei Municipal Ordinária $n^{\circ}$ 7.258, de 6 de julho de 2012. Institui o Plano Municipal de Cultura e dá outras providências. Disponível em: $<$ https://leismunicipais.com.br/a/sc/j/joinville/lei-ordinaria/2012/725/7258/lei-ordinarian-7258-2012-institui-o-plano-municipal-de-cultura-de-joinville-e-da-outrasprovidencias>. Acesso em: 25 ago. 2018.

KOSELLECK, Reinhart. Futuro passado: contribuição à semântica dos tempos históricos. Rio de Janeiro: Contraponto, 2006.

MACHADO, Diego Finder. Em amparo às marcas do passado: os profissionais do patrimônio e a construção de uma ordem patrimonial em Joinville-SC. In: ENCONTRO NACIONAL DE HISTÓRIA ORAL, 13., Porto Alegre. Anais... Porto Alegre: UFRGS, 2016. 16 p.

Redimidos pelo passado: seduções nostálgicas de uma cidade contemporânea. (Joinville, 1997-2008). 178 f. Dissertação (Mestrado)-Universidade do Estado de Santa Catarina, Florianópolis, 2009.

MENESES, Ulpiano Toledo Bezerra de. O campo do patrimônio cultural: uma revisão de premissas. In: FÓRUM DO PATRIMÔNIO CULTURAL, 1., Ouro Preto. Anais... Ouro Preto, 2009. p. 25-38.

PADRÓS, Enrique Serra. Sobre a História do Tempo Presente. Dossiê História do Tempo Presente, ditaduras de segurança nacional e arquivos repressivos. In: Revista do Programa de Pós Graduação em História Tempo e Argumento. Udesc: Florianopolis, v.1, n.1, p. 30-45, jan./jun. 2009.

RADUN, Denis Fernando. $O$ (des)tombamento em questão: (des)patrimonialização de bens culturais tombados pelo órgão federal de preservação no Brasil (1937-2015). 215 f. Dissertação (Mestrado)-Universidade da Região de Joinville, Joinville, 2016. 
RIBAS, Geovanna Paoça Primor; SOUSA FILHO, Carlos Frederico Marês de. A judicialização das políticas públicas e o Supremo Tribunal Federal. Direito, Estado e Sociedade, Rio de Janeiro, n. 44, jan./jun. 2014, p. 36-50.

SANTA CATARINA. Decreto Estadual $n^{\circ}$ 7.439, de 24 de abril de 1979. Institui a Fundação Catarinense de Cultura (FCC) e dá outras providências. Disponível em: http://redespecula.pro.br/wp-content/uploads/2017/08/legislacao.pdf . Acesso em: 25 ago. 2018.

Lei Estadual n. ${ }^{\circ}$ 5.846, de 22 de dezembro de 1980. Dispõe sobre a proteção do patrimônio cultural do Estado e dá outras providências. Disponível em: http://redespecula.pro.br/wp-content/uploads/2017/08/legislacao.pdf Acesso em: 25 ago. 2018.

SILVA, Bruno. A construção do campo do patrimônio cultural: políticas de preservação, instâncias, mecanismos e agentes culturais em Joinville, SC (1951-1984). 195 f. Dissertação (Mestrado)-Universidade do Estado de Santa Catarina, Florianópolis, 2016. 